\title{
ASK1 resistant neuroblastoma is deficient in activation of p38 kinase
}

\author{
Y Arvidsson ${ }^{\star, 1}$, TS Hamazaki ${ }^{1,2}$, H Ichijo $^{2}$ and K Funa ${ }^{1}$ \\ 1 Department of Medical Cell Biology, Institute of Anatomy and Cell Biology, \\ Göteborg University, Box 420, SE-405 30 Gothenburg, Sweden \\ ${ }^{2}$ Laboratory of Cell Signaling, Department of Hard Tissue Engineering, Division \\ of Biomatrix, Graduate School, Tokyo Medical and Dental University, 1-5-45 \\ Yushima Bunkyo-ku, Tokyo 113-8549, Japan \\ * Corresponding author: Y Arvidsson, Department of Medical Cell Biology, \\ Institute of Anatomy and Cell Biology, Göteborg University, Box 420, SE-405 \\ 30 Gothenburg, Sweden. Tel: +46 31773 3331; Fax: +46 31773 3330; \\ E-mail: yvonne.arvidsson@anatcell.gu.se
}

Received 7.3.01; revised 11.6.01; accepted 11.6.01 Edited by DC Altieri

\begin{abstract}
Apoptosis Signal-regulating Kinase 1 (ASK1) is known to either induce apoptosis or differentiation in various cell lines of neuronal origin. We analyzed the effect of the constitutively active mutant of ASK1 (ASK1- $\Delta \mathrm{N}$ ) in an adenoviral vector in four neuroblastoma cell lines, two murine, $\mathrm{C} 1300$ and NXS2, and two human, SH-SY5Y and IMR-32. Already after $24 \mathrm{~h}$ upon infection, C1300 and SH-SY5Y cells arrested in growth when judged by $\left[{ }^{3} \mathrm{H}\right]$ thymidine incorporation, and the majority of the cells demonstrated apoptotic appearance, which was confirmed by DNA-laddering in gel electrophoresis. In contrast, NXS2 and IMR-32 cell lines remained unaffected. Immunoblotting revealed strongly phosphorylated p38 MAPK accompanied by weakly phosphorylated JNK in C1300 and SH-SY5Y, whereas none of these kinases were activated by adenoviruses expressing the kinase negative ASK 1 mutant or $\beta$-galactosidase. There was no expression of phosphorylated kinases in IMR-32 cells, but NXS2 showed a faint band of phosphorylated p38 MAPK. Addition of thep38MAPKspecificinhibitor,SB203580, protected C1300and SH-SY5Y cells from apoptosis induced by ASK1- $\triangle N$. The antineoplastic agent, paclitaxel, activates ASK1 and JNK, and promotes the in vitroassembly of stable microtubules. Addition of $10 \mathrm{nMpaclitaxel}$ sensitised the NXS2 celllinetoASK1-induced cell death. Our results indicate that ASK1 induces apoptosis in neuroblastoma cells mainly via the P38 MAPK pathway, and resistant neuroblastoma cells can be sensitised to ASK1 by paclitaxel. Cell Death and Differentiation (2001) 8, 1029-1037.
\end{abstract}

Keywords: neuroblastoma; ASK1; apoptosis; p38 MAPK; JNK

Abbreviations: ASK1, apoptosis signal-regulating kinase; $\triangle \mathrm{N}, \mathrm{N}$ terminal deletion; ECL, enhanced chemoluminescence; $H A$, hemagglutinin; HRP, horseradish peroxidase; IL-1, interleukin-1; JNK, c-jun N-terminal kinase; NGF, nerve growth factor; p38 MAPK, p38 mitogen activated protein kinase; TNF, tumour necrosis factor; WT, wild-type

\section{Introduction}

Neuroblastoma occurs in the sympathetic nervous system, being one of the most common solid tumours of infancy. ${ }^{1}$ The tumour progression is very heterogeneous, ranging from the most favourable case where the tumour differentiates to benign ganglioneuroma or spontaneously disappears ${ }^{2}$, to the other extreme where the patient has disseminated disease at the time of diagnosis. Despite aggressive treatment involving surgical removal of primary tumour, multiagent regimes of chemotherapy and high-dose chemo- and radiotherapy followed by autologous bone marrow transplantation, the prognosis for such a patient is poor, with 5 years survival rate of less than $40 \%$. $^{3}$ There is a need to develop new therapeutic approaches that are more effective and less toxic than the current regimes, improving the survival rate of patients with advanced neuroblastoma.

Programmed cell death occurs in the nervous system during normal maturation but also in neurodegenerative diseases and strokes. ${ }^{4-7}$ Apoptosis also takes place within the primary neuroblastoma as the tumour cells move away from the fibrovascular stroma. ${ }^{8}$ Positive correlations have been observed between frequency of apoptotic cells and favourable outcome of patient. ${ }^{9}$ The mechanism behind the spontaneous regression of neuroblastoma is unknown, but one hypothesis suggests it was due to apoptosis. ${ }^{10}$

Apoptosis Signal-regulating Kinase 1 (ASK1) is a Mitogen Activated Protein Kinase Kinase Kinase (MAPKKK), which is typically induced by TNF- $\alpha$ and activates the SEK1-JNK and MKK3/MKK6-p38 signalling cascades. ${ }^{11}$ These two pathways are activated by environmental stress, such as UV radiation and osmotic shock as well as the pro-inflammatory cytokines, tumour necrosis factor (TNF) and interleukin-1 (IL1). ${ }^{12,13}$ ASK1 is also linked to the CD95 signalling pathway through the binding and activation of the DAXX protein. ${ }^{14}$ Since many chemotherapeutic drugs activate this pathway, ASK1 has a central role in cytotoxicity caused by chemotherapy. Microtubulesinterfering agents are used in the treatment of neuroblastoma, and it has been reported that ASK1 is involved in the signal transduction pathways initiated by microtubule interfering agents such as paclitaxel. ${ }^{15,16}$ This antineoplastic agent promotes the in vitro assembly of microtubules, stabilising the formed polymers against depolymerisation. ${ }^{17}$ The formation of a rigid microtubular network prevents cell division, causing block in mitosis in the G2/M phase. ${ }^{18}$

ASK1 induces apoptosis in a variety of cells such as mink lung epithelial cells. ${ }^{11}$ In cells of the nervous system, rat primary sympathetic neurones and NGF-treated rat pheochromocytoma, PC12 cells have been reported to undergo apoptosis by overexpression of ASK1. ${ }^{19}$ In contrast, Takeda et al. ${ }^{20}$ found that moderate expression of ASK1 induces differentiation and survival of naïve PC12 cells. 
The aim of this study was to investigate whether ASK1 induces apoptosis or differentiation in neuroblastoma cells and to analyze the activation of its downstream signalling pathways. We express the constitutively active mutant of ASK1, which has an N-terminal deletion $(A S K 1-\Delta N)^{21}$ in four different neuroblastoma cell lines, two of murine and two of human origin. We also investigate the effect of the combination of $A S K 1-\Delta N$ and paclitaxel.

\section{Results}

\section{The effect of ASK1- $\Delta \mathrm{N}$ in C1300, NXS2, SH-SY5Y and IMR-32 cells}

The effect of ASK1 in neuroblastoma cells was investigated by infecting four different cell lines, C1300, NXS2, SH-SY5Y and IMR-32 with recombinant adenoviruses encoding for the wild-type ASK1 (AdASK1-WT), the constitutively active mutant of ASK1 (AdASK1- $\Delta N)$, the dominant negative ASK1 (AdASK1-K709R) or $\beta$-galactosi- dase $(\beta$-gal). The growth patterns of the four cell lines were monitored by $\left[{ }^{3} \mathrm{H}\right]$ thymidine incorporation during the course of 3 days (Figure 1). When the cells were grown in medium containing $10 \%$ serum, the growth of C1300 and SH-SY5Y cells was almost totally inhibited when transduced with AdASK1- $\Delta \mathrm{N}$ at an m.o.i. of 100. While ASK1K709R, ASK1-WT or $\beta$-gal at the same m.o.i. did not affect the growth during 3 days. The $\left[{ }^{3} \mathrm{H}\right]$ thymidine incorporation was suppressed already $24 \mathrm{~h}$ after infection by AdASK1$\triangle \mathrm{N}$. NXS2 and IMR-32 showed growth patterns similar to the controls, and therefore they were not as sensitive as C1300 and SH-SY5Y cells to ASK1- $\Delta \mathrm{N}$ mediated cell growth inhibition. To investigate the dose response of the four different cell lines to ASK $1-\Delta N,\left[{ }^{3} \mathrm{H}\right]$ thymidine incorporation was performed at 2 and 3 days after infection in medium supplemented with $1 \%$ serum. This revealed that C1300 and SH-SY5Y are more sensitive than NXS2 and IMR-32 to the growth inhibitory effect of ASK1- $\Delta \mathrm{N}$, and the inhibition occurred in a dose dependent manner. We could also see that NXS2 was weakly inhibited when medium containing $1 \%$ serum was used (Figure 2 ).

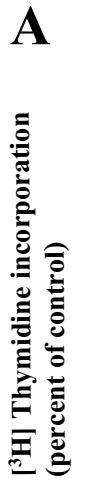

NXS2

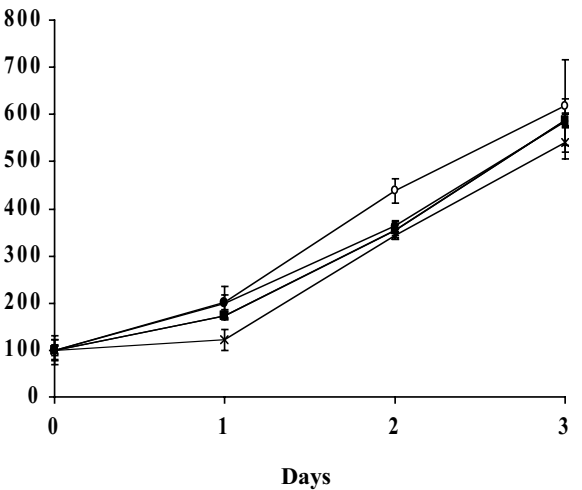

C

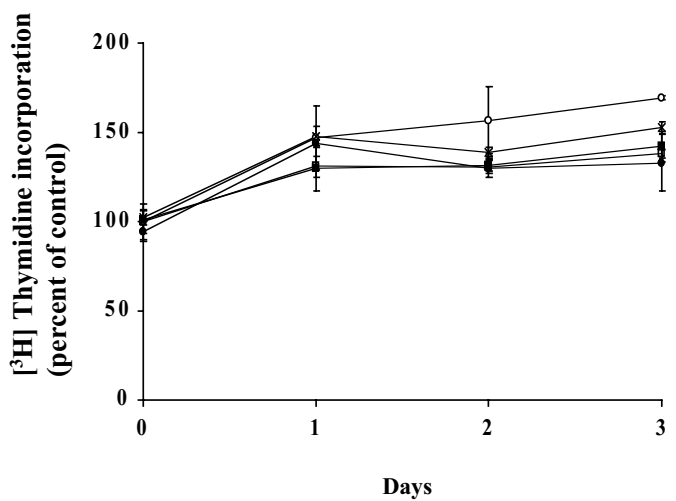

B

$\mathbf{C 1 3 0 0}$

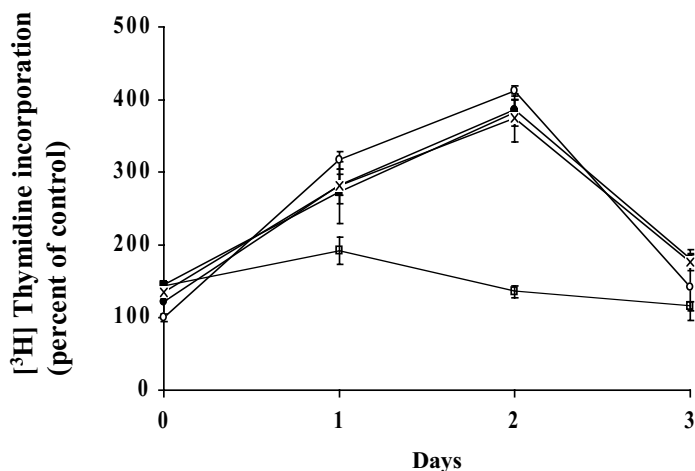

D SH-SY5Y

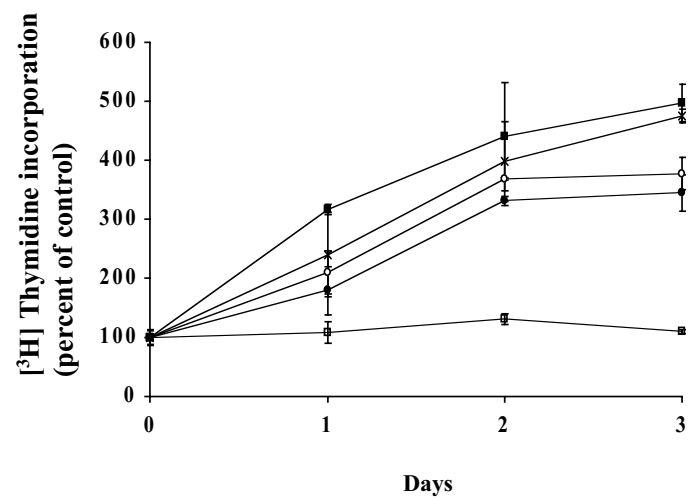

Figure 1 Time course of ASK1- $\Delta \mathrm{N}$ dependent cell growth in different neuroblastoma cell lines. The cells were infected on day 0 with adenovirus vectors expressing $\beta$-galactosidase ( $(\bullet)$, or ASK1: wild-type, ASK1 -WT $(\times)$, constitutively active, ASK1- $\Delta \mathrm{N}(\square)$, kinase negative. ASK1-K709R ( $\mathbf{\square})$, and uninfected (O). $\left[{ }^{3} \mathrm{H}\right]$ Thymidine incorporation was determined in medium containing $10 \%$ serum. Data shown are per cents of control that was set at the value of each cell line on the day of infection, indicated as means of triplicate values \pm S.D. (A) and (B) the mouse neuroblastoma cell lines NXS2 and C1300. (C) and (D) the human cell lines IMR-32 and SH-SY5Y 

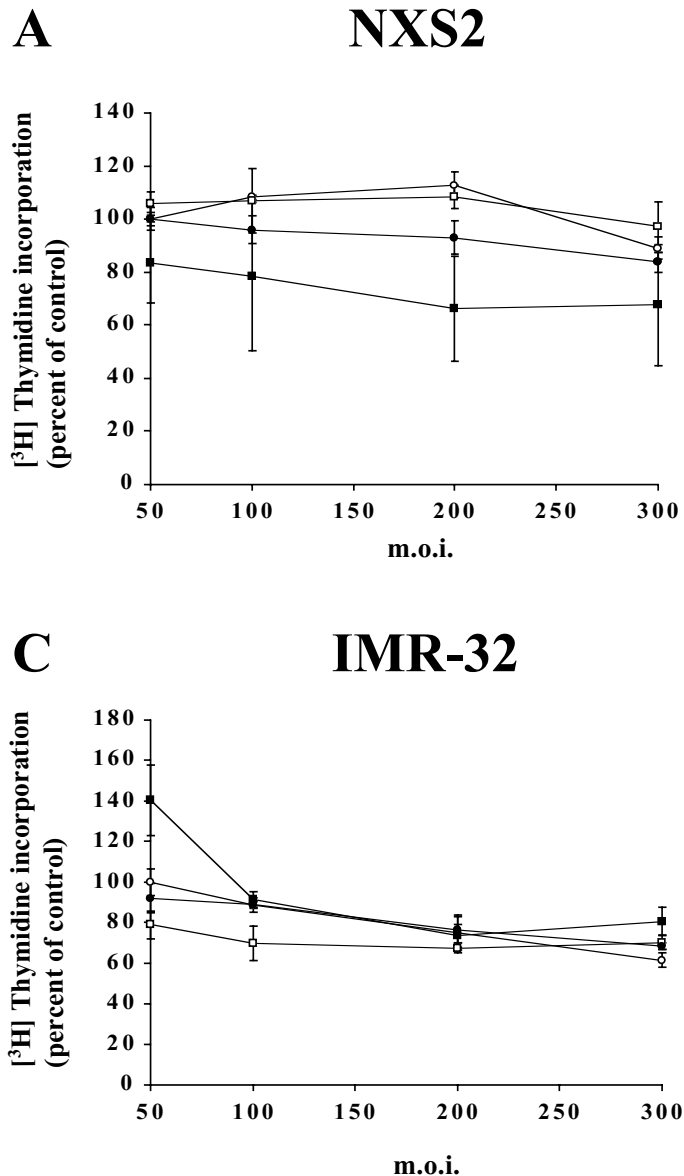

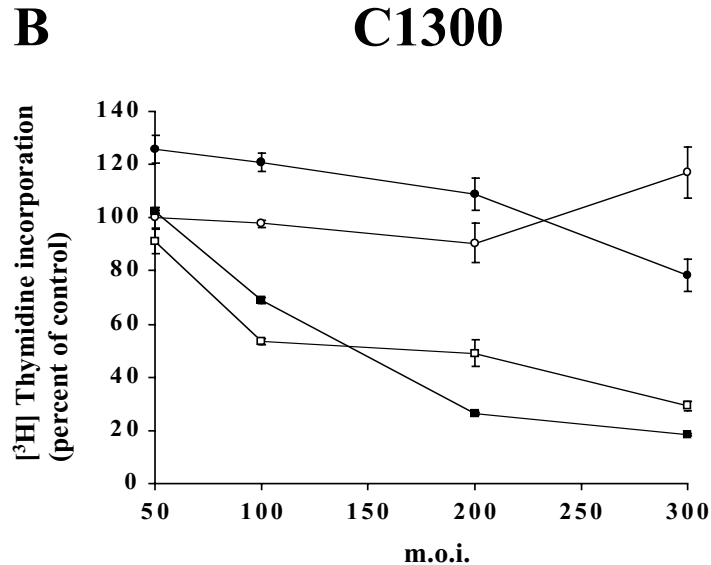

D SH-SY5Y

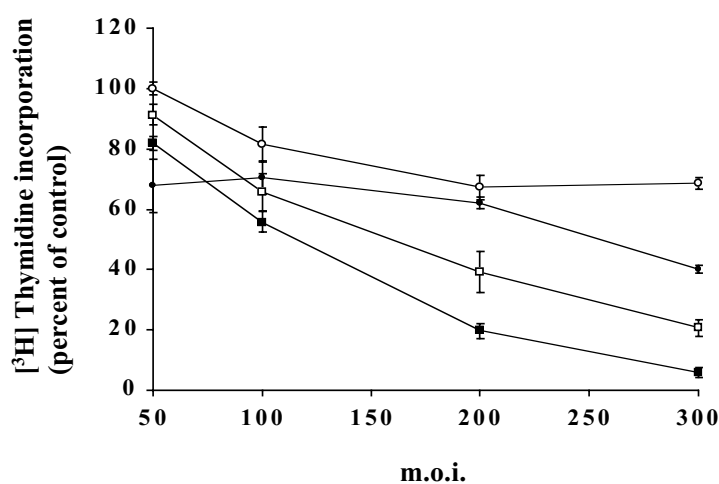

Figure 2 Dose dependent growth due to AdASK1- $\Delta$ N monitored by $\left[{ }^{3} H\right]$ thymidine incorporation. (A) and (B) NXS2 and C1300. (C) and (D) IMR-32 and SH-SY5Y. ASK1-K709R $(O)$ and ASK1- $\Delta \mathrm{N}(\square) 2$ days after infection, ASK1-K709R $(-)$ and ASK1- $\Delta \mathrm{N}(\mathbf{\square}) 3$ days after infection at an m.o.i. of $50-300$. Data shown are per cents of control that was set at the value of each cell line on the day of infection, means of triplicate values \pm S.D.

\section{ASK1- $\Delta \mathrm{N}$ promotes apoptosis in neuroblastoma cells}

To establish the cause of the ASK $1-\Delta \mathrm{N}$ induced growth inhibition in $\mathrm{C} 1300$ and SH-SY5Y cells, a Cell Death Detection ELISA ${ }^{\text {PLUS }}$ (CDD) assay was performed (Figure $3 A)$. This assay quantitatively measures the level of nucleosomes released in the cytoplasm by using antibodies against DNA and histones. There was a 3.4-fold higher level of apoptosis in SH-SY5Y cells infected with AdASK1- $\triangle \mathrm{N}$ compared to cells infected with AdASK1-K709R. The level of apoptosis in $\mathrm{C} 1300$ was only 1.3-fold higher. The assay was performed on day 2 after infection in $\mathrm{C} 1300$ cells due to high background on day 3 . When the results from the $\left[{ }^{3} \mathrm{H}\right]$ thymidine incorporation and the CDD assay were compared, a low level of apoptosis could be found in C1300 cells in the CDD assay. To verify the results of the CDD assay, FACS analysis for annexin $\mathrm{V}$ and propidium lodide staining was performed. Annexin $V$ has a high affinity for phosphatidylserine that becomes exposed on the external surface of cells during apoptosis. Compared with AdASK-K709R-infected cells, AdASK-DN-infected cells displayed an increased annexin V positive population in both SH-SY5Y and C1300 (Figure 3B). In the case of $\mathrm{C} 1300$, the majority of cells remained unaffected by $A S K 1-\Delta N$ and only a small population underwent apoptosis. These results from FACS analysis are concordant with those from CDD assay. Microscopic examination revealed that cells expressing ASK $1-\Delta \mathrm{N}$, but not the control ASK1-K709R, underwent cell death with morphological changes characteristic of apoptosis, such as nuclear condensation and membrane blebbing in $\mathrm{C} 1300$ and $\mathrm{SH}$ SY5Y cells but not in NXS2 and IMR-32 cells (Figure 4).

\section{ASK1- $\Delta \mathrm{N}$ induces phosphorylation of p38 MAP kinase and c-Jun terminal kinase (JNK) in the two sensitive cell lines SH-SY5Y and C1300}

ASK1 has been shown to phosphorylate the stress activated SEK1-JNK and MKK3/MKK6-p38 signalling cascades in COS cells. In this study, immunoblotting was performed to investigate the activation of these two signalling pathways in neuroblastoma cells over-expressing ASK1. The cells were harvested $24 \mathrm{~h}$ after infection, and immunoblotting of the lysates was performed using antibodies that specifically recognise phosphorylated p38 MAP kinase (p-p38) and phosphorylated SAPK/JNK ( $p$-JNK) (Figure 5). The results suggest an increased phosphorylation and therefore activation of p38 in the two ASK1-sensitive cell lines, C1300 and 
A

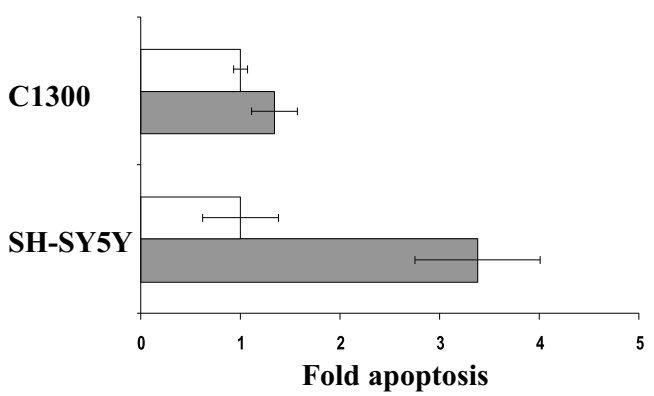

B

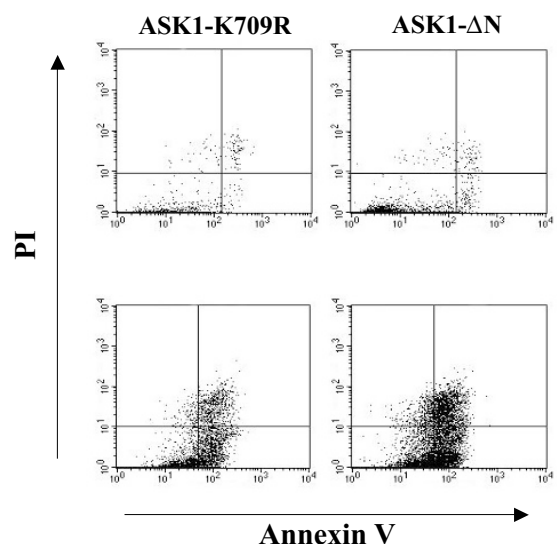

$\mathbf{C 1 3 0 0}$

SH-SY5Y

Figure 3 (A) Comparison of the levels of apoptosis induced by AdASK1- $\Delta \mathrm{N}$ (grey bars) and AdASK1-K709R (white bars) measured by Cell Death Detection ELISA ${ }^{\text {PLUS }}$. SH-SY5Y cells were cultured in medium containing $1 \%$ for 3 days and $C 1300$ cells for 2 days after infection at an m.o.i. of 300. Data shown are means of triplicate values \pm S.D. (B) FACS analysis of annexin $V$ and propidium iodide staining of ASK1- $\triangle \mathrm{N}$ induced apoptosis in SH-SY5Y and C1300. Compared with AdASK1-K709 infected cells, AdASK1- $\Delta$ N increased in the annexin V-positive population in SH-SY5Y and C1300, although the positive population in $\mathrm{C} 1300$ is small. $\mathrm{C} 1300$ and SH-SY5Y were infected with AdASK1-K709 or AdASK1- $\Delta \mathrm{N}$ at an m.o.i. of 300 and cultured in medium containing $1 \%$ for 2 and 3 days, respectively

SH-SY5Y, when compared with the same cells expressing the kinase negative mutant, ASK1-K709R. NXS2 showed only a marginal activation of $\mathrm{p} 38$ and we were not able to detect any activation in IMR-32 cells. In contrast to p38, the level of JNK activation was only slightly increased in one of the cell lines, C1300. To confirm that the cell lines had intact signalling cascades leading to p38 and JNK activation and to verify that the antibodies would detect the phosphorylated form of the antigens, lysate from cells treated with $0.5 \mathrm{M}$ sorbitol for 15 min was used as a positive control.

\section{The p38 MAPK inhibitor, SB203580, protects the cells from ASK1- $\Delta \mathrm{N}$ mediated apoptosis}

Western blot analysis suggested that $A S K 1-\Delta N$ induced apoptosis in SH-SY5Y and C1300 cells through the p38 MAPK pathway. Therefore, we examined the occurrence of DNA fragmentation, and the requirement of p38 for AdASK1- $\triangle \mathrm{N}$ mediated apoptosis in $\mathrm{C} 1300$ and $\mathrm{SH}-\mathrm{SY} 5 \mathrm{Y}$ cells by using the p38 MAPK specific inhibitor, SB203580 (Figure 6). We first analyzed the expression of $A S K 1-\Delta N$ to exclude the possibility that the presence of SB203580 decreased the expression. Equal amount of proteins was applied to Western blot and probed with the HRP conjugated anti-HA antibody (3F10), showing almost equal level of expression. We next analyzed whether the treatment of cells with SB203580 inhibited the DNA fragmentation. After 48 and $60 \mathrm{~h}$, DNA laddering was clearly observed in the SH-SY5Y cells infected with AdASK1- $\triangle \mathrm{N}$ (Figure 6A), which markedly decreased when the cells were treated with SB203580 (100 nM). In C1300 cells, DNA fragmentation was observed at 16 and $20 \mathrm{~h}$ after infection and was also suppressed by the presence of SB203580 (800 nM) (Figure 6B). In this experiment we used $10 \%$ FBS containing medium for SH-SY5Y cells since SB203580 itself was highly cytotoxic in a low serum condition as seen in $\left[{ }^{3} \mathrm{H}\right]$ thymidine incorporation (data not shown). Lower concentration of SB203580 was also chosen for that reason. Earlier time points for $\mathrm{C} 1300$ were analyzed due to high background at later stages.

\section{ASK1- $\Delta$ N combined with paclitaxel increases cell death}

The two murine cell lines NXS2 and C1300 were further analyzed for the combined effect of ASK1- $\Delta N$ and paclitaxel. The cells were infected with AdASK $1-\Delta \mathrm{N}$ or $\operatorname{Ad} \beta$-gal at an m.o.i. of 100 , and $16 \mathrm{~h}$ after infection, paclitaxel was added to a final concentration of $0.01 \mu \mathrm{M}$ (Figure 7). The cell growth was measured by $\left[{ }^{3} \mathrm{H}\right]$ thymidine incorporation after further 8,24 and $48 \mathrm{~h}$. Western blot analysis had earlier shown that ASK1- $\Delta \mathrm{N}$ was expressed at $16 \mathrm{~h}$ post infection (data not shown). At the same time period of exposure, NXS2 cells were more sensitive to paclitaxel than $\mathrm{C} 1300$ cells and there was clearly an increased killing in both cell lines when paclitaxel was added to the ASK $1-\Delta \mathrm{N}$ expressing cells.

\section{Discussion}

The primary purpose of this study was to investigate whether overexpression of ASK1 would induce apoptosis in neuroblastoma cells. In order to investigate the effects of ASK1- $\Delta \mathrm{N}$ on cellular growth or viability, we measured $\left[{ }^{3} \mathrm{H}\right]$ thymidine incorporation. ASK1- $\Delta \mathrm{N}$ dependent growth inhibition was observed in SH-SY5Y and C1300. NXS2 also showed a small tendency to growth depression. It is difficult to directly compare the cell lines to each other since there are differences in doubling time and in adenovirus infectivity between the cells, although the infection by the recombinant adenoviruses at an m.o.i. of 300 nearly transduced $100 \%$ of the cells in each cell line when estimated by $\beta$-gal expression. Otherwise, differences in the expression level of adenovirus transduced genes in these cell lines may play critical roles in their responses. The expression level of ASK1- $\Delta \mathrm{N}$ and ASK1-K709R was comparable when estimated by Western blots at $24 \mathrm{~h}$ after infection.

In this study, we show that ASK $1-\Delta \mathrm{N}$ promotes cell death due to apoptosis rather than differentiation in $\mathrm{SH}$ SY5Y and C1300 cells. Immunoblotting and enzymatic 
A
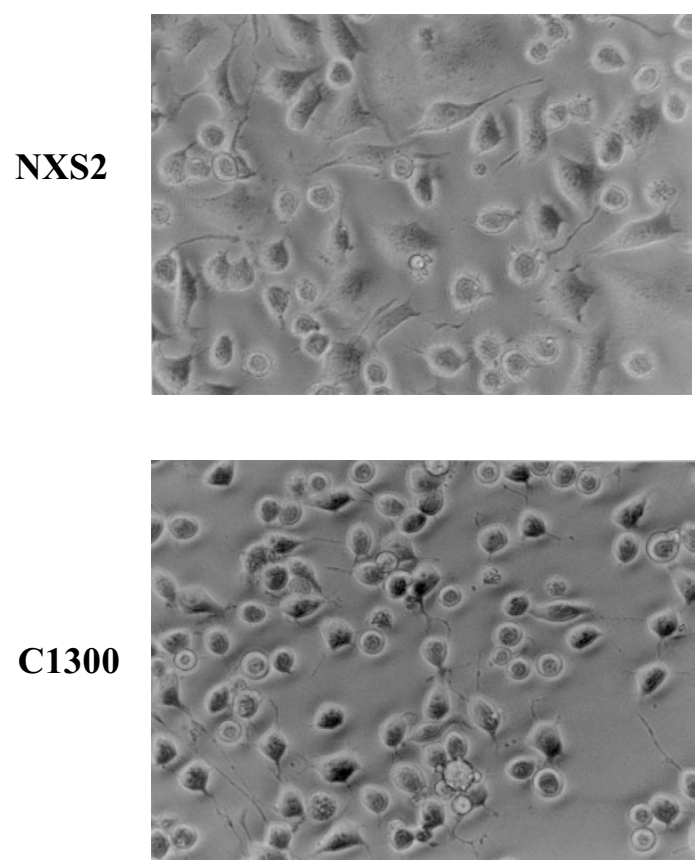

B

IMR-32
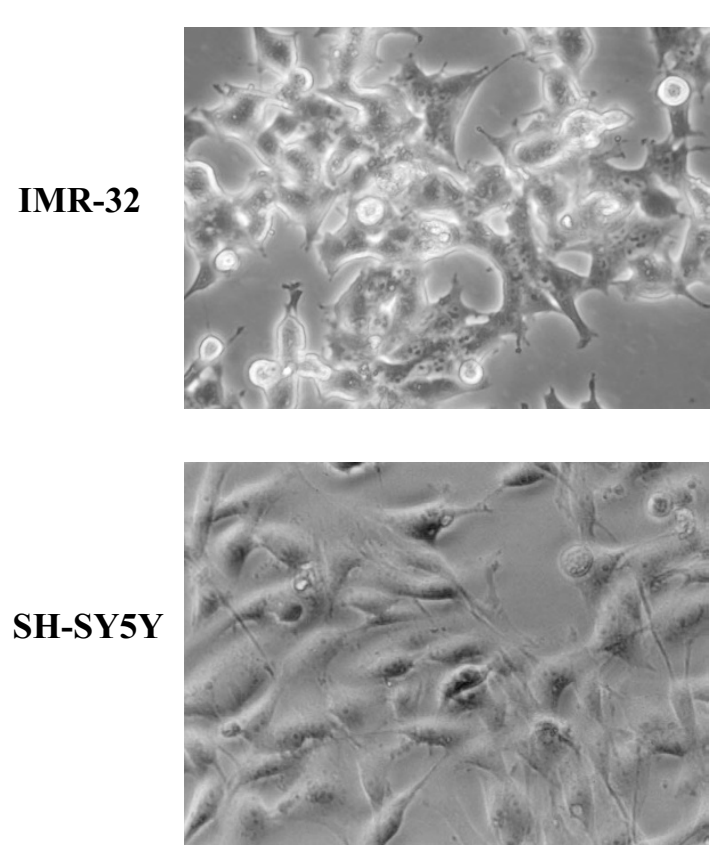

ASK1- $\Delta \mathbf{N}$
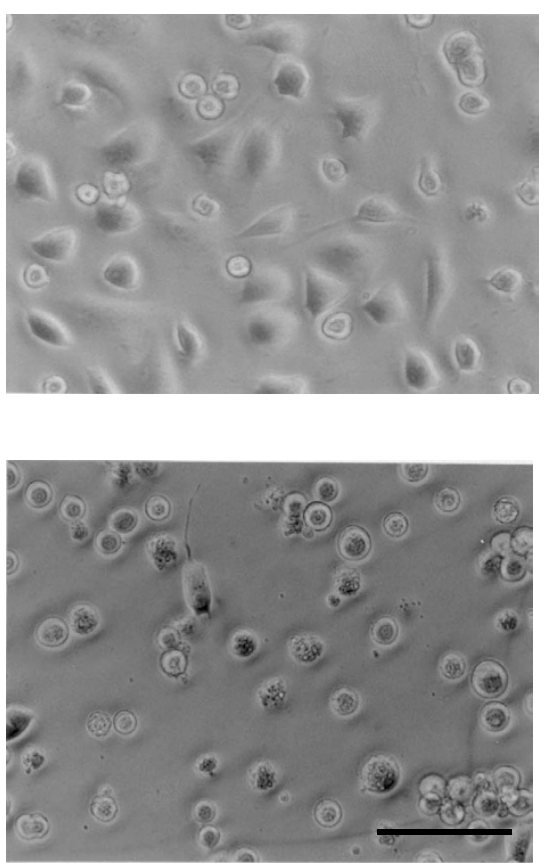

ASK1- $\Delta \mathbf{N}$
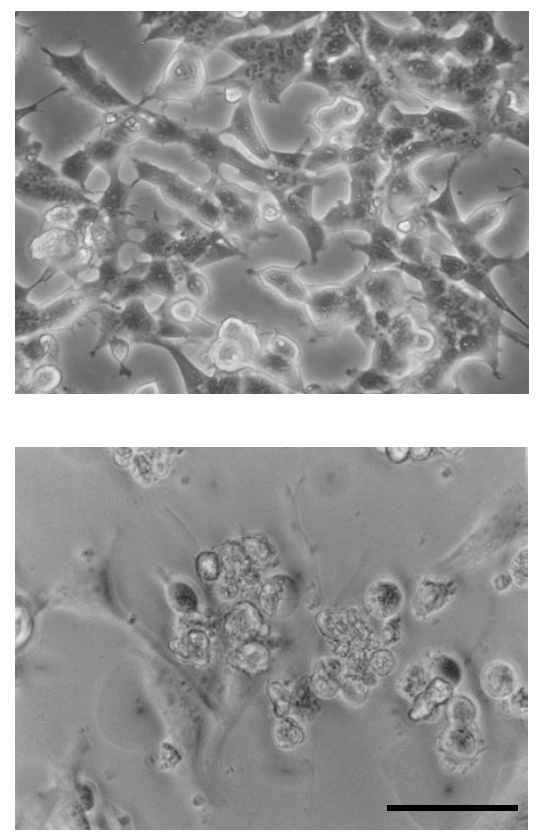

Figure 4 Phase-contrast micrographs showing the morphology of (A) NXS2 and C1300, (B) IMR-32 and SH-SY5Y, infected at an m.0.i. of 300 with adenovirus encoding either ASK1-K709R or ASK1- $\Delta \mathrm{N}$. At the point of infection the medium was changed from that containing $10 \%$ serum to $1 \%$ serum and then cultured for 3 days. Scale bar: $10 \mu \mathrm{m}$

analysis showed the sign of Caspase 3 activation in both of these cell lines. In the case of $\mathrm{C} 1300$, displaying a weak apoptotic signal in both CDD assay and annexin V analysis, we conclude that the majority of the cell population goes into cell cycle arrest, while the remaining cells go into apoptosis. C1300 has a shorter doubling time than SH-SY5Y, resulting in a rapid generation of new cell population with diluted $A S K 1-\Delta \mathrm{N}$ expression since adenovirus was used for the gene transfer. In fact, the level of phosphorylated p38 in C1300 began to decrease already 
A

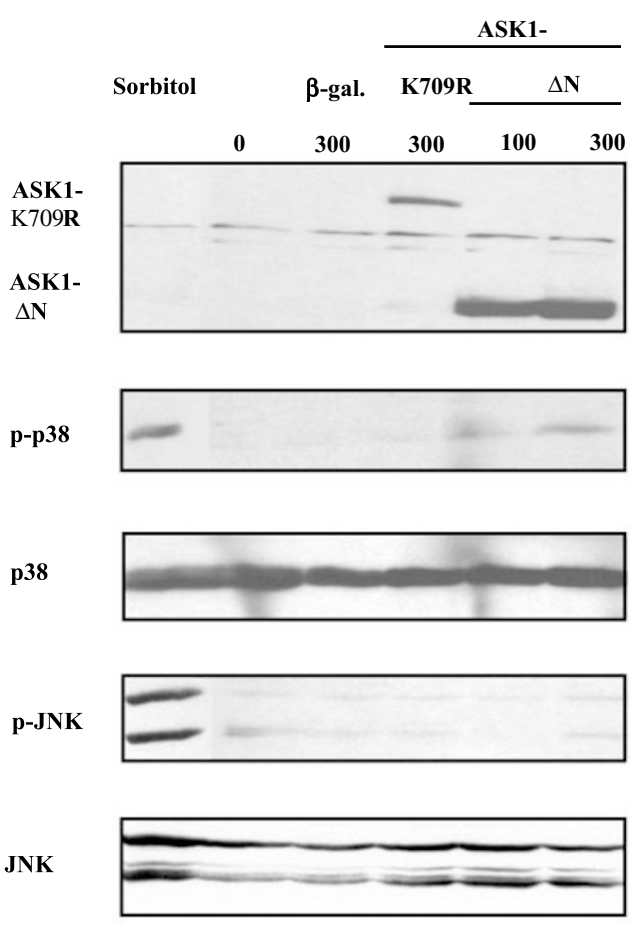

B

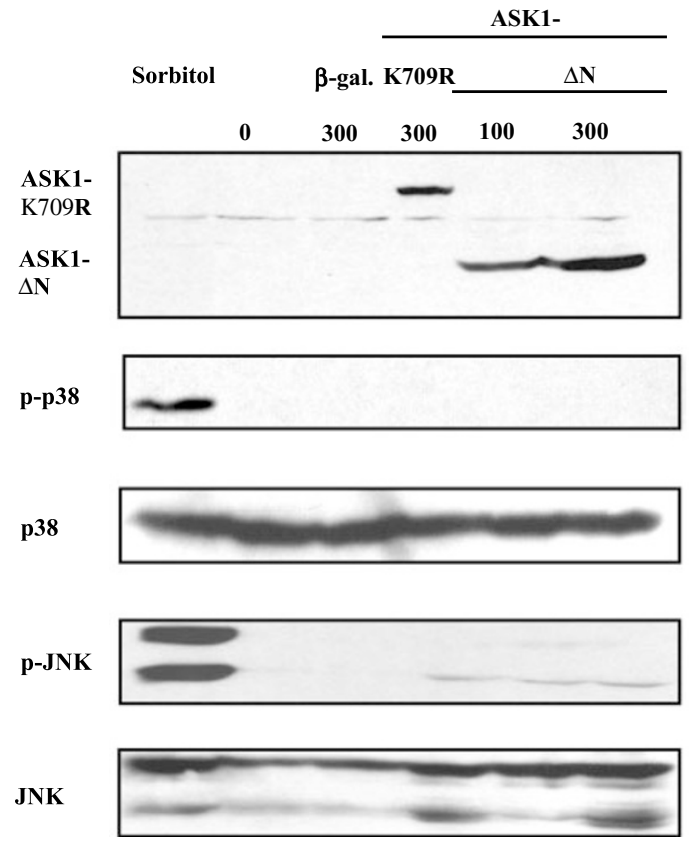

C1300
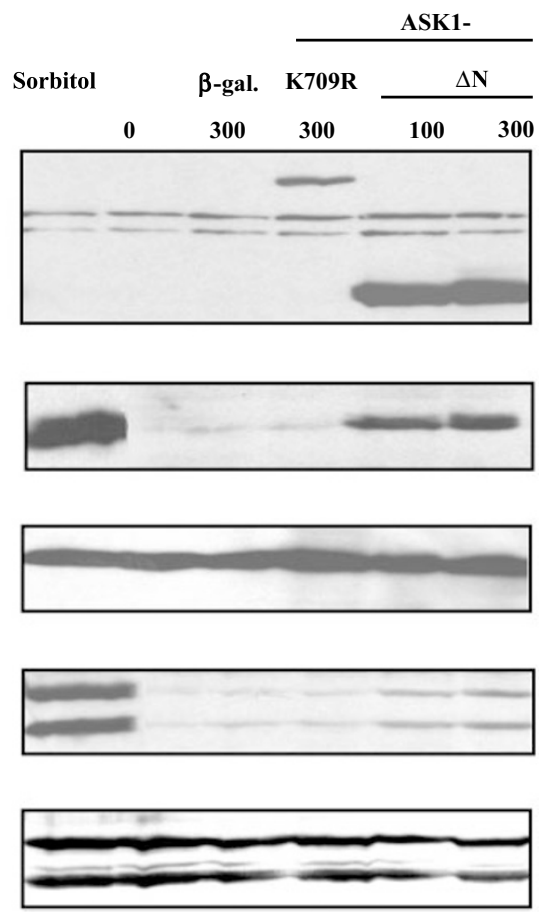

SH-SY $5 Y$
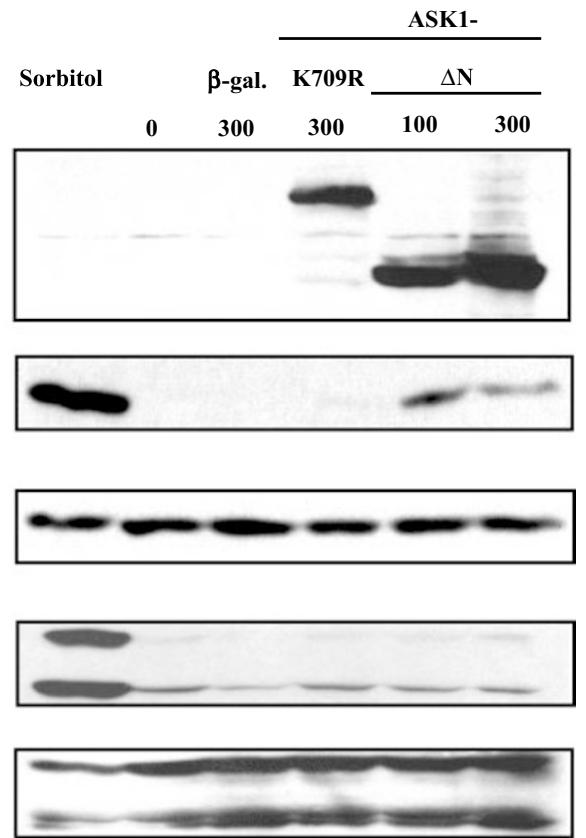

Figure 5 Immunoblotting of whole lysates from cells over-expressing $\beta$-gal, ASK1KM, and ASK1- $\Delta$ N infected at a m.o.i. of 100-300. (A) NXS2 and C1300. (B) IMR-32 and SH-SY5Y. Antibodies against the HA tagged ASK1- $\mathrm{N}$ and ASK1-K709R, phosphorylated p38 MAP kinase (p-p38) and c-Jun kinase (p-JNK), total p38 MAP kinase (p38) and c-Jun kinase (JNK) were used. As a positive control, the lysate of the cells exposed to $0.5 \mathrm{M}$ sorbitol for $15 \mathrm{~min}$ was used

on day 2 compared with the level seen on day 1 . This agrees with the recent report demonstrating the importance of sustained activation of p38 for apoptosis. ${ }^{22}$
It is known that serum withdrawal induces apoptosis, and it has also been shown that $1 \%$ serum increases the ASK1 activity in Mv1Lu cells. ${ }^{11}$ Therefore, most experi- 
A

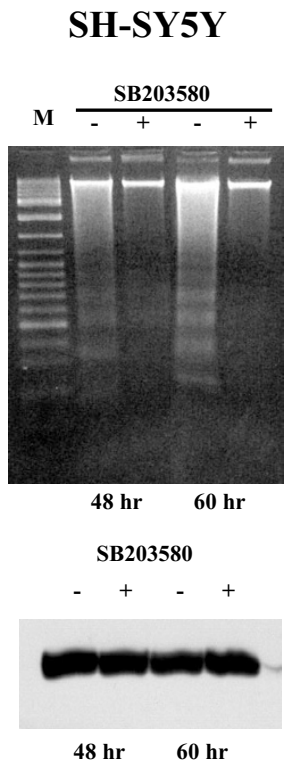

B
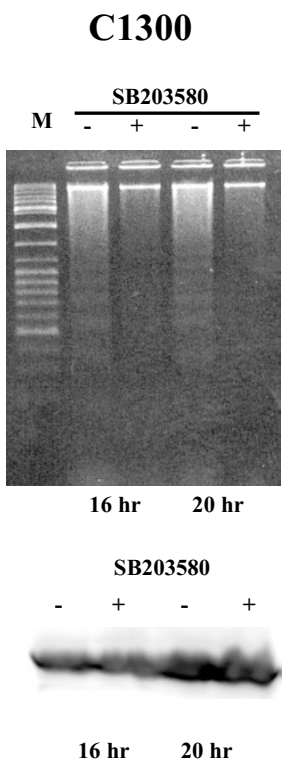

Figure 6 Upper panels: The p38 MAPK specific inhibitor, SB203580, protected the ASK1 sensitive cell lines SH-SY5Y (A) and C1300 (B) from apoptosis. DNA fragmentation was observed $48 \mathrm{~h}$ after infection of AdASK1$\triangle \mathrm{N}$ in SH-SY5Y and increased after $60 \mathrm{~h}$. $\mathrm{C} 1300$ cells showed DNA-laddering at 16 and $20 \mathrm{~h}$ after infection. In both cases, DNA fragmentation was reduced in the presence of SB203580 ( $100 \mathrm{nM}$ for SH-SY5Y cells and $800 \mathrm{nM}$ for $\mathrm{C} 1300$ cells). Lower panels: The presence of SB203580 did not affect the expression of ASK1- $\Delta \mathrm{N}$ in SH-SY5Y (A) and C1300 (B) examined by immunoblotting using a HRP conjugated anti-HA antibody

ments were conducted in medium containing $1 \%$ serum. We could not detect any clear morphological sign of differentiation by ASK1 in any of those cell lines, in contrast to $\mathrm{PC} 12$ cells that differentiated in the same condition. ${ }^{20}$ The PC12 differentiation seems to occur following p38 activation. However, in the cell lines examined herein, p38 activation was associated with the induction of cell death. The non-responding cell lines, NXS2 and IMR32, contained much lower expression levels of phosphorylated p38. We could detect a small difference in the phosphorylated JNK that was also increased in one of the sensitive cell lines, C1300. In the two murine cell lines we analyzed, NXS2 is more differentiated than $\mathrm{C} 1300$ since it is a hybrid of $\mathrm{C} 1300$ and sympathetic ganglion cells. However, NXS2 does not respond to ASK1-induced apoptosis whereas C1300 does, in contrast to PC12, which upon differentiation by NGF preferentially goes into apoptosis. The reason for this difference is not clear, but it is possible that interactions between various intracellular signalling molecules affect responses of cells to ASK1. In fact, several factors have been reported to regulate and interact with the ASK1 signalling pathway. Thus, thioredoxin binds directly to the $\mathrm{N}$-terminal part of ASK1 under reducing conditions, which however cannot be involved in this study. ${ }^{21}$ The ASK1 activity is also inhibited by cytoplasmic p $21^{\text {cip } 1 / W A F 1}$ that forms a complex with $A S K 1^{23}$ and by the 14-3-3 protein that binds specifically to Ser-967 of ASK1. ${ }^{24}$ Cells in various conditions would therefore respond differently, depending on a balance between the activated pathways within the cells.
A

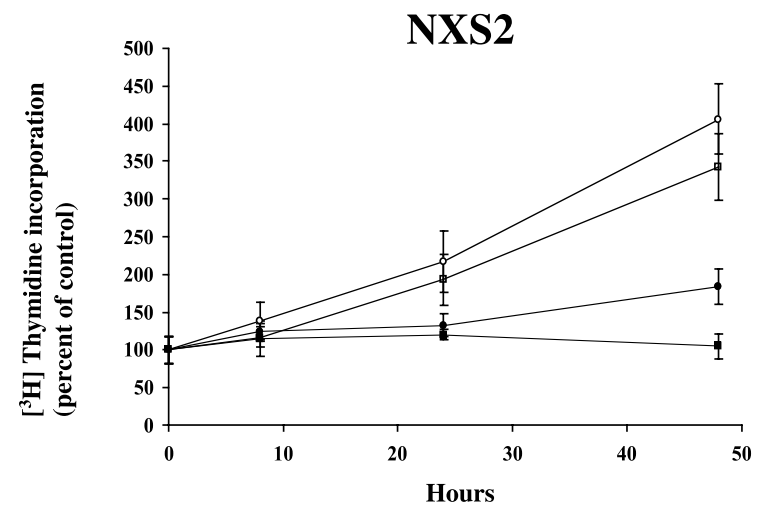

B

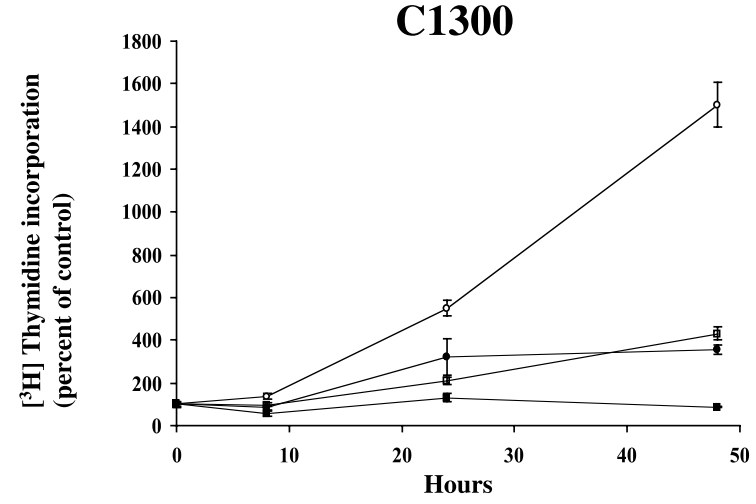

Figure $7\left[{ }^{3} \mathrm{H}\right]$ Thymidine incorporation, 8, 24, 48 h following addition of $0.01 \mu \mathrm{M}$ paclitaxel. Data shown are per cents of controls that were set at the value of each cell line at the time of addition of paclitaxel. (A) NXS2 cells. (B) C1300 cells. Ad $\beta$-gal+DMSO (O), Ad $\beta$-gal+paclitaxel (O), AdASK1$\Delta \mathrm{N}+\mathrm{DMSO}(\square)$, AdASK1- $\Delta \mathrm{N}+$ paclitaxel ( $\boldsymbol{\square})$. Means of triplicate values; bars \pm S.D.

It has been shown that MYCN amplification sensitises neuroblastoma to apoptosis following their exposure to interferon $\gamma^{25}$ or cytotoxic drugs. ${ }^{26}$ In this aspect, it is interesting that ASK1 enhances the protein stability of c-Myc through phosphorylation at Ser-62 and Ser-71, which is required for c-Myc-dependent apoptosis by ASK1-signalling. ${ }^{27}$ However, MYCN is a prognostic marker for neuroblastoma with poor outcome, and despite high MYCN expression many neuroblastoma are resistant to chemotherapy. The reason for this is not clear, but it is possible that apoptosis pathways in neuroblastoma might be impaired. Our results showed that SH-SY5Y that has no MYCN gene amplification $^{28}$ was sensitive to ASK1-induces apoptosis, whereas IMR-32 that has amplification ${ }^{29,30}$ did not show any response at all. We were not able to detect any activation of p38 MAPK in IMR-32 cells although the same kinase could be activated by osmotic shock given by sorbitol.

The plasma concentration of paclitaxel in patients under the treatment is $0.21-13.0 \mu \mathrm{M}^{31}$ In our experiments, when $10 \mathrm{nM}$ paclitaxel in combination with ASK1 was used, we were able to show an increased cytotoxic effect compared with the effects obtained by either one of these molecules. The cytotoxic effect of paclitaxel is considered to be mainly due to the phosphorylation of JNK in addition to the direct activation of ASK $1 .{ }^{15}$ It is possible that the combination of 
both stress-activated kinases activates a large number of target molecules important for apoptosis. Thus, the effect of the microtubule-interfering agents used in the clinic can be potentiated by the combination with ASK1 gene transfer, which might be a possible alternative treatment. It would be valuable to investigate whether there exist proteins that counteract the ASK1-p38 pathway in certain neuroblastoma cells. The search for this mechanism is under way in our laboratory.

\section{Materials and Methods}

\section{Cells and cell culture}

Dr. RA Reisfeld (La Jolla) provided the mouse neuroblastoma cell lines, C1300 and NXS2. NXS2 is a hybrid of C1300 and sympathetic ganglion cells. ${ }^{32}$ Dr. S Påhlman (Malmö) provided the two human cell lines, SH-SY5Y and IMR-32. All cell lines were maintained routinely in medium supplemented with $10 \%$ foetal bovine serum (FBS), penicillin $100 \mathrm{IU} / \mathrm{ml}$ and streptomycin $100 \mu \mathrm{g} / \mathrm{ml}$ in a $5 \% \mathrm{CO}_{2}$ atmosphere at $37^{\circ} \mathrm{C}$. The medium used was either Dulbecco's modified Eagle's medium, DMEM (NXS2, SH-SY5Y), or RPMI 1640 (C1300, IMR-32).

\section{Adenovirus vectors}

The recombinant adenoviruses encoding for $\beta$-gal $(\operatorname{Ad} \beta$-gal), the HAtagged wild-type of ASK1 (AdASK-WT), the kinase negative ASK1 (AdASK1-K709R), and the constitutively active ASK1 (AdASK1- $\Delta N$ ), were described previously. ${ }^{21,33,34}$ The adenovirus was propagated in 293 cells to produce high titer stocks. Cells were infected for 3-4 days, harvested and lysed by five cycles of freeze/-thawing. The lysate was centrifuged at 3000 r.p.m. for $20 \mathrm{~min}$ at $4^{\circ} \mathrm{C}$ and the stocks were kept at $-70^{\circ} \mathrm{C}$.

\section{ASK1- $\Delta \mathrm{N}$-dependent inhibition of $\left[{ }^{3} \mathrm{H}\right]$ thymidine incorporation}

Cells were seeded at a density of $1.5 \times 10^{4}$ cells per well in 24-well culture plates (Techno Plastic Products) in medium containing $10 \%$ serum and infected on the next day with recombinant adenovirus at a multiplicity of infection (m.o.i.) of 50-300. At the indicated time points the cells were incubated with $0.6 \mu \mathrm{Ci}\left[{ }^{3} \mathrm{H}\right]$ thymidine per $\mathrm{ml}$ medium for $4 \mathrm{~h}$, and precipitated with $5 \% \mathrm{TCA}$ at $4^{\circ} \mathrm{C}$. The precipitate was then dissolved in $1 \mathrm{M} \mathrm{NaOH}$, neutralised with $1 \mathrm{M}$ $\mathrm{HCl}$, and the ${ }^{3} \mathrm{H}$ incorporation into the DNA was determined. The cells were washed once and the medium was changed to contain $1 \%$ serum at the point of infection in the following experiments: (a) Dose response of cells expressing ASK1- $\Delta \mathrm{N}$ (Figure 2); (b) The combined effect of ASK1 $-\Delta \mathrm{N}$ and paclitaxel (Sigma) (Figure 7). Paclitaxel was dissolved in DMSO to a concentration of $10 \mathrm{mM}$ and then added to the cells to a final concentration of $0.01 \mu \mathrm{M}$ at $16 \mathrm{~h}$ after the NXS2 and $\mathrm{C} 1300$ cells were infected with $\mathrm{Ad} \beta$-gal and AdASK1- $\Delta \mathrm{N}$ at an m.o.i. of 100 .

\section{Apoptosis assay}

A total of $3 \times 10^{3}$ cells were seeded in $0.2 \mathrm{ml}$ medium in each well in a microtiter plate. On the next day the medium was changed to $1 \%$ FBS and the cells were infected with AdASK1- $\Delta$ N and AdASK1-K709R at an m.o.i. of 300 . Apoptosis was assayed using the Cell Death Detection ELISA ${ }^{\text {PLUS }}$ assay (Roche) according to the vendor's instruction. SH-SY5Y was assayed 3 days and $\mathrm{C} 13002$ days after infection.

\section{FACS analysis}

Annexin $\mathrm{V}$ staining was performed using the Annexin-V-FLURO staining kit (Roche), according to manufacturer's instructions. In short, $5 \times 10^{4}$ cells were infected with AdASK1-K709R or AdASK1$\Delta \mathrm{N}$ at an m.o.i. of 300 in medium containing $1 \%$ serum. The cells were harvested by trypsin treatment, washed twice with PBS and then resuspended in $100 \mu \mathrm{l}$ binding buffer containing annexin VFITC and propidum iodide (PI). After $15 \mathrm{~min}$ incubation, the samples were diluted with $400 \mu \mathrm{l}$ binding buffer and the fluorescence emitted by the cells $\left(1 \times 10^{4}\right.$ cells/sample) was analyzed using a FACS Calibur flow cytometer (Becton Dickinson). SH-SY5Y was assayed 3 days and C1300 2 days after infection.

\section{Western blot analysis}

Equal numbers of cells from each cell line were seeded in medium containing $10 \%$ serum, and on the next day they were washed and medium containing $1 \%$ serum was added at the same time as the cells were infected with recombinant adenovirus. Twenty-four hours after infection the cells were washed with $1 \times$ PBS and lysed in buffer containing $150 \mathrm{mM} \mathrm{NaCl}, 50 \mathrm{mM}$ Tris$\mathrm{HCl}$ at $\mathrm{pH} 8.0,1 \%$ Nonidet $\mathrm{P}-40,0.5 \%$ deoxycholate, and $0.1 \%$ SDS, $1 \mathrm{mM}$ phenylmethylsulphonyl fluoride and $50 \mathrm{kIU} / \mathrm{ml}$ Trasylol. Cell debris was removed by centrifugation and the protein concentration in each lysate was determined by using DC Protein Assay (Bio-Rad). The same amount of protein, $80 \mu \mathrm{g}$, was separated on $10 \%$ SDS-polyacrylamide gel electrophoresis and then electroblotted onto PVDF membrane by semi-dry transfer (Bio-Rad). After blocking for $1 \mathrm{~h}$ with $5 \%$ milk in Tris-buffered saline with $0.1 \%$ Tween 20 (TBS-T) the membranes were probed with the primary antibodies. The primary antibodies used were phospho-specific rabbit polyclonal antibodies to p38 MAP kinase (Thr-180/Tyr-182), SAPK/JNK (Thr-183/Tyr-185) as well as rabbit polyclonal antibodies to p38 MAP kinase and JNK, and the secondary antibody was anti-rabbit IgG conjugated with horseradish peroxidase (HRP; New England Bio-Labs). We also used the HRP-conjugated rat monoclonal antibody (3F10, Roche) to detect the haemagglutinin (HA)-tagged ASK1-K709R and ASK1$\Delta \mathrm{N}$. The signals were detected by enhanced chemiluminescence (ECL; New England Bio-Labs).

\section{DNA fragmentation analysis}

Approximately $2 \times 10^{6}$ of SH-SY5Y and $\mathrm{C} 1300$ cells were seeded in $10 \mathrm{~cm}$ dishes and infected with AdASK1- $\Delta \mathrm{N}$. Following the infection, SH-SY5Y cells were cultured for 48 and $60 \mathrm{~h}$ in DMEM medium containing 10\% FBS with or without 100 nM SB203580 (Calbiochem). In a low serum condition this inhibitor showed a toxic effect on this cell line. The $\mathrm{C} 1300$ cells were cultured for 16 and $20 \mathrm{~h}$ in RPMI containing $1 \%$ FBS with or without $800 \mathrm{nM}$ SB203580. The cells were then washed with PBS and lysed with $400 \mu$ l of a buffer containing $20 \mathrm{mM}$ Tris- $\mathrm{HCl}, 10 \mathrm{mM}$ EDTA and $0.6 \%$ SDS (pH 7.5) by rotation for $20 \mathrm{~min}$ at room temperature. To remove large molecular weight DNA, $100 \mu \mathrm{l}$ of $5 \mathrm{M} \mathrm{NaCl}$ was added to the lysate and incubated overnight at $4^{\circ} \mathrm{C}$. After centrifugation at $21000 \times g$ for $1 \mathrm{~h}$, the supernatant was 
recovered and incubated with $0.5 \mathrm{mg} / \mathrm{ml}$ ribonuclease $A$ at $42^{\circ} \mathrm{C}$ for $2 \mathrm{~h}$, and then with $0.2 \mathrm{mg} / \mathrm{ml}$ of proteinase $\mathrm{K}$ at $42^{\circ} \mathrm{C}$ for $1 \mathrm{~h}$. The small molecular weight DNA fragments were then further purified by phenol, phenol-chloroform extraction, and ethanol precipitation. DNA laddering was analyzed by $2 \%$ agarose gel electrophoresis and ethidium bromide staining.

\section{Acknowledgements}

We thank M Fujii for the help with adenovirus, and F Watt, V Sumantran and $U$ Molander for valuable discussions. This work was supported by grants from Barncancerfonden, Swedish Medical Research Council, Cancerfonden, the Inga and Arne Lundberg Foundation, STINT, the Swedish Institute, the Jubileumsfonden, and the Medical Faculty at Göteborg University.

\section{References}

1. Young Jr. JL, Ries LG, Silverberg E, Horm JW and Miller RW (1986) Cancer incidence, survival, and mortality for children younger than age 15 years. Cancer. 58: $598-602$

2. Jaffe N (1976) Neuroblastoma: review of the literature and an examination of factors contributing to its enigmatic character. Cancer Treat Rev. 3: 61-82

3. Stram DO, Matthay KK, O'Leary M, Reynolds CP, Haase GM, Atkinson JB, Brodeur GM and Seeger RC (1996) Consolidation chemoradiotherapy and autologous bone marrow transplantation versus continued chemotherapy for metastatic neuroblastoma: a report of two concurrent Children's Cancer Group studies. J. Clin. Oncol. 14: 2417-2426

4. Clarke PG (1990) Developmental cell death: morphological diversity and multiple mechanisms. Anat. Embryol. 181: 195-213

5. Henderson CE (1996) Programmed cell death in the developing nervous system. Neuron 17: $579-585$

6. Pettmann Band Henderson CE (1998) Neuronal cell death. Neuron 20:633-647

7. Dirnagl U, ladecola C and Moskowitz MA (1999) Pathobiology of ischaemic stroke: an integrated view. Trends Neurosci. 22: 391-397

8. Hoehner JC, Gestblom C, Olsen L and Pahlman S (1997) Spatial association of apoptosis-related gene expression and cellular death in clinical neuroblastoma. Br. J. Cancer 75: 1185-1194

9. Gestblom C, Hoehner JC and Pahlman S (1995) Proliferation and apoptosis in neuroblastoma: subdividing the mitosis-karyorrhexis index. Eur. J. Cancer 31A: $458-463$

10. Pritchard J and Hickman JA (1994) Why does stage 4s neuroblastoma regress spontaneously? Lancet 344: 869-870

11. Ichijo $H$, Nishida $E$, Irie $K$, ten Dijke $P$, Saitoh $M$, Moriguchi $T$, Takagi $M$, Matsumoto K, Miyazono Kand Gotoh Y (1997) Induction of apoptosis by ASK1, a mammalian MAPKKK that activates SAPK/JNK and p38 signaling pathways. Science 275: $90-94$

12. Davis RJ (1994) MAPKs: new JNK expands the group. Trends Biochem. Sci. 19: $470-473$

13. Karin M (1995) The regulation of AP-1 activity by mitogen-activated protein kinases. J. Biol. Chem. 270: 16483-16486

14. Chang HY, Nishitoh H, Yang X, Ichijo H and Baltimore D (1998) Activation of apoptosis signal-regulating kinase 1 (ASK1) by the adapter protein Daxx. Science 281: $1860-1863$

15. Wang TH, Wang HS, Ichijo H, Giannakakou P, Foster JS, Fojo T and Wimalasena $\mathrm{J}(1998)$ Microtubule-interfering agents activate c-Jun N-terminal kinase/stressactivated protein kinase through both Ras and apoptosis signal-regulating kinase pathways. J. Biol. Chem. 273: 4928-4936
16. Wang TH, Popp DM, Wang HS, Saitoh M, Mural JG, Henley DC, Ichijo H and Wimalasena J (1999) Microtubule dysfunction induced by paclitaxel initiates apoptosis through both c-Jun $\mathrm{N}$-terminal kinase (JNK)-dependent and independent pathways in ovarian cancer cells. J. Biol. Chem. 274: 8208-8216

17. Schiff PB, Fant J and Horwitz SB (1979) Promotion of microtubule assembly in vitro by taxol. Nature 277: 665-667

18. Schiff PB and Horwitz SB (1980) Taxol stabilizes microtubules in mouse fibroblast cells. Proc. Natl. Acad. Sci. USA 77: 1561-1565

19. Kanamoto T, Mota M, Takeda K, Rubin LL, Miyazono K, Ichijo Hand Bazenet CE (2000) Role of apoptosis signal-regulating kinase in regulation of the C-Jun Nterminal kinase pathway and apoptosis in sympathetic neurons. Mol. Cell. Biol. 20: $196-204$

20. Takeda K, Hatai T, Hamazaki TS, Nishitoh H, Saitoh M and Ichijo H (2000) Apoptosis signal-regulating kinase 1 (ASK1) induces neuronal differentiation and survival of PC12 cells. J. Biol. Chem. 275: 9805-9813

21. Saitoh M, Nishitoh H, Fujii M, Takeda K, Tobiume K, Sawada Y, Kawabata M, Miyazono K and Ichijo $\mathrm{H}$ (1998) Mammalian thioredoxin is a direct inhibitor of apoptosis signal-regulating kinase (ASK) 1. EMBO J. 17: 2596-2606

22. Tobiume K, Matsuzawa A, Takahashi T, Nishitoh H, Morita K, Takeda K, Minowa $\mathrm{O}$, Miyazono K, Noda T and Ichijo H (2001) ASK1 is required for sustained activations of JNK/p38 MAP kinases and apoptosis. EMBO Rep. 21: 222-228

23. Asada M, Yamada T, Ichijo H, Delia D, Miyazono K, Fukumuro K and Mizutani S (1999) Apoptosis inhibitory activity of cytoplasmic 21 (Cip1/WAF1) in monocytic differentiation. EMBO J. 18: 1223-1234

24. Zhang $L$, Chen J and Fu H (1999) Suppression of apoptosis signal-regulating kinase 1 -induced cell death by 14-3-3 proteins. Proc. Natl. Acad. Sci. USA 96: $8511-8515$

25. Lutz W, Fulda S, Jeremias I, Debatin KM and Schwab M (1998) MycN and IFNgamma cooperate in apoptosis of human neuroblastoma cells. Oncogene 17: $339-346$

26. Fulda S, Lutz W, Schwab M and Debatin KM (1999) MycN sensitizes neuroblastoma cells for drug-induced apoptosis. Oncogene. 18: 1479-1486

27. NoguchiK, Kokubu A, Kitanaka C, Ichijo Hand Kuchino Y (2000) ASK1-signaling promotes c-Myc protein stability during apoptosis. Biochem. Biophys. Res. Commun. 281: 1313-1320

28. Biedler JL, Helson L and Spengler BA (1973) Morphology and growth, tumorigenicity, and cytogenetics of human neuroblastoma cells in continuous culture. Cancer Res. 33: 2643-2652

29. Kanda N, Tsuchida Y, Hata J, Kohl NE, Alt FW, Latt SA and Utakoji T (1987) Amplification of IMR-32 clones 8, G21, and N-myc in human neuroblastoma xenografts. Cancer Res. 47: 3291-3295

30. Kato H, Okamura K, Kurosawa Y, Kishikawa T and Hashimoto K (1989) Characterization of DNA rearrangements of $\mathrm{N}$-myc gene amplification in three neuroblastoma cell lines by pulsed-field gel electrophoresis. FEBS Lett. 250: $529-535$

31. Rowinsky EK and Donehower RC (1993) The clinical pharmacology of paclitaxel (Taxol). Semin. Oncol. 20: 16-25

32. Greene LA, Shain W, Chalazonitis A, Breakfield X, Minna J, Coon HG and Nirenberg M (1975) Neuronal properties of hybrid neuroblastoma X sympathetic ganglion cells. Proc. Natl. Acad. Sci. USA 72: 4923-4927

33. Saito I, Oya Y, Yamamoto K, Yuasa T and Shimojo H (1985) Construction of nondefective adenovirus type 5 bearing a 2.8-kilobase hepatitis B virus DNA near the right end of its genome. J. Virol. 54: 711-719

34. Miyake S, Makimura M, Kanegae Y, Harada S, Sato Y, TakamoriK, Tokuda Cand Saito I (1996) Efficient generation of recombinant adenoviruses using adenovirus DNA-terminal protein complex and a cosmid bearing the full-length virus genome. Proc. Natl. Acad. Sci. USA 93: 1320-1324 